\title{
An Investigation into the Limitations of the Combined dv/dt and di/dt Protection Technique for Compact d.c. Distribution Systems
}

\author{
Allan Smith \\ Dept. Electronic and Electrical \\ Engineering \\ University of Strathclyde \\ Glasgow, UK \\ pwb14144@uni.strath.ac.uk
}

\author{
Dong Wang \\ Dept. Electronic and Electrical \\ Engineering \\ University of Strathclyde \\ Glasgow, UK \\ d.wang@strath.ac.uk
}

\author{
Abdullah Emhemed \\ Dept. Electronic and Electrical \\ Engineering \\ University of Strathclyde \\ Glasgow, UK \\ abdullah.emhemed@strath.ac.uk
}

\author{
Graeme Burt \\ Dept. Electronic and Electrical \\ Engineering \\ University of Strathclyde \\ Glasgow, UK \\ graeme.burt@strath.ac.uk
}

\begin{abstract}
-d.c. distribution networks interfaced by two-level voltage source converters (VSCs) are characterised by rapid fault current development, which places severe time constraints on d.c. protection. A proposed solution to ease this is the implementation of advanced converters with current management capabilities such as modular multilevel converter (MMC). However, the limited fault current caused by MMC will make the widely used LV current-based protection less effective. A new method, targeted utility-scale LVDC distribution networks at conditions with limited fault current, combining $\mathrm{dv} / \mathrm{dt}$ and $\mathrm{di} / \mathrm{dt}$ has been proposed in literature with promising results for fast and selective protection. However, further investigation must be carried out to determine its applicability and limitations for protecting future compact d.c. distribution systems. This paper presents an investigation into the selective capabilities of the combined $\mathrm{dv} / \mathrm{dt}$ and $\mathrm{di} / \mathrm{dt}$ protection technique for a range of fault scenarios. The study considers the effects of sampling frequency, fault locations, and the network architecture with the aim of determining the limitations of the protection method. A simplified converter model with active fault current limiting and blocking capabilities is built in PSCAD/EMTDC and implemented in a radial and ring compact d.c. distribution network to facilitate the study.
\end{abstract}

\section{Keywords-LVDC, d.c. protection, limited fault current}

\section{INTRODUCTION}

The evolution of power electronics has brought developments in converter and protection technologies casting light on d.c. power distribution. d.c. distribution systems have recently been considered as an attractive, and increasingly practical choice to integrate growing numbers of low carbon technologies such as electric vehicles, heat pumps, micro wind turbines, and solar photovoltaic power generation [2]-[4]. However, the rapid fault development, a characteristic of d.c. networks, places severe time constraints on d.c. protection systems to detect, locate, and interrupt d.c. faults within the required time scale [5]. This is in addition to the requirements of higher rating equipment. One potential solution is the use of advanced converter technologies such as the modular multilevel converters (MMC) which can actively limit and block fault currents easing the protection operating time constraints and enabling the utilisation of lower rating assets [6].

A review of recent literature shows a move towards the allelectric ship using d.c. power distribution [3][7]-[10], IEEE 1709-2010 states that converters deployed within d.c. shipboard systems should have the ability to limit short-circuit fault currents [11]. Using converters with active fault current management capabilities can reduce the requirements for using overrated power electronic devices to withstand fault currents. However, limiting fault currents may reduce the effectiveness of widely used protection methods such as overcurrent protection. A technique combining the rate of change of voltage $(\mathrm{dv} / \mathrm{dt})$, and rate of change of current $(\mathrm{di} / \mathrm{dt})$ has been proposed which has shown promising results for scenarios with reduced fault currents [1]. The method has a potential to be used on shipboard protection system, however, the breadth of fault scenarios must be increased to identify its applicability.

Therefore, this paper presents alternative fault scenarios and the resulting performance of the combined $\mathrm{dv} / \mathrm{dt}$ and $\mathrm{di} / \mathrm{dt}$ protection technique. Section II reviews the challenges associated with d.c. protection and how limited fault currents present further problems. Section III briefly outlines the operation of the combined $\mathrm{dv} / \mathrm{dt}$ and $\mathrm{di} / \mathrm{dt}$ protection technique and discusses the potential issues that could negatively impact its operation. Section IV provides a description of the target network architectures and how the fault current limiting and blocking behavior of the converter is modelled. Section V presents the response of the protection technique in the fault scenarios expected to introduce operational issues. Conclusions are drawn in section VI on the capabilities of the technique with potential improvements being discussed for scenarios resulting in less effective performance.

\section{Challenges For EXISTing D.C. Protection Schemes AGAINST LIMITED FAULT CURRENTS IN COMPACT SYSTEMS}

Selectivity of protection becomes an issue with compact systems. As system size is reduced, the impedance between two fault locations is reduced resulting in the faults fully propagating through the network in reduced times. 
The rapid development of peak fault current results in challenging time constraints being placed on d.c. protection systems. This is a challenge for mechanical circuit breakers as their operating time is relatively long $(12.5 \mathrm{~ms})$ [12]. To address this, significant research is being carried out into the development of solid-state (SSCBs) and hybrid circuit breakers which have exhibited fault clearing times of $0.4 \mathrm{~ms}$ and $6.5 \mathrm{~ms}$ respectively [13]. Whilst these present a solution to the harsh time constraints, they currently are not commercially available and are financially expensive solutions [14]. Recently, advanced converters such as modular multilevel converters (MMC) have been introduced in LVDC systems [15]. Their active fault current management capabilities increase the allowable operating time for protection systems enabling mechanical breakers to be used.

More compact systems such as ships and aircrafts present the added complication of space and weight criticality. Aircrafts require a high level of selectivity so that in the event of a fault, the loss of supply is minimal to ensure maximum control of the aircraft is maintained. To exploit the efficiency advantages of d.c., the weight of the electrical system must be minimized. This reduction in weight could come from lower rated electrical equipment or fewer protection devices, which can be achieved by using advanced converters such as MMC to reduce the fault levels Error! Reference source not found.

Under the fault conditions with limited fault currents, the use of $\mathrm{dv} / \mathrm{dt}$ can be used to detect faults, however, its behaviour lacks fault direction information makes it difficult to locate the fault. Current-based techniques such as overcurrent and di/dt protection may be significantly impacted by reduced fault levels presenting further challenges. However, the sign of $\mathrm{di} / \mathrm{dt}$ still can be used to determine if a fault is located upstream or downstream of a relay even if the fault current is limited. By combining $\mathrm{dv} / \mathrm{dt}$ and $\mathrm{di} / \mathrm{dt}$, the benefits of both can be taken advantage of with $\mathrm{dv} / \mathrm{dt}$ being used to detect the fault and di/dt providing directional information for the fault with respect to the relay. The concept of the protection scheme that uses the combined $\mathrm{dv} / \mathrm{dt}$ and $\mathrm{di} / \mathrm{dt}$ to detect and locate d.c. fault is introduced in the following section.

\section{COMBINED DV/DT AND DI/DT BASED D.C. PROTECTION SCHEME}

\section{A. Introduction of protection algorithm}

The combined $\mathrm{dv} / \mathrm{dt}$ and $\mathrm{di} / \mathrm{dt}$ has been investigated in radial network configuration and has shown promising results for fast and selective operation for LVDC in utility applications [1]. The scheme detects and locates a fault based on the magnitudes of $\mathrm{dv} / \mathrm{dt}$ and the signs of $\mathrm{di} / \mathrm{dt}$. Thresholds for $\mathrm{dv} / \mathrm{dt}$ and $\mathrm{dv} / \mathrm{dt} * \mathrm{di} / \mathrm{dt}$ are set at each relay, which are representative of a fault on the edge of the relays zone of protection. The $\mathrm{dv} / \mathrm{dt}$ will be negative during a fault, however this alone does not guarantee selective relay operation. The introduction of a di/dt measurement allows the relay to distinguish between the upstream and downstream faults, which would exhibit positive and negative di/dt respectively. By taking the product of $\mathrm{dv} / \mathrm{dt}$ and $\mathrm{di} / \mathrm{dt}$ and comparing it to a pre-set $\mathrm{dv} / \mathrm{dt} * \mathrm{di} / \mathrm{dt}$ threshold, different faults may be both detected and located, allowing for selective operation.

\section{B. Identification of the potential limitations}

The combined $\mathrm{dv} / \mathrm{dt} * \mathrm{di} / \mathrm{dt}$ technique has shown promise when applied to a radial land-based LVDC network, however there are certain fault scenarios that could result in protection failure. These are discussed as follows.

\section{1) Influences of different fault locations}

The radial branch in Fig. 1 shows three potential fault locations. F1 occurs upstream of bus 2, F2 is located downstream of bus 2 and relay 'b', and F3 occurs immediately upstream of bus 3. Ideally, relay 'a', at Bus 1, should trip for F1 only. Relay 'b', at bus 2, should trip for F2 and F3, only. However, due to there being little distance between F1 and F2, both relay ' $a$ ' and relay ' $b$ ' are likely to trip simultaneously for F2 resulting in the portion of the network between bus 1 and bus 2 being undesirably isolated.

Furthemore, F1 has the potential to cause an undesirable $\mathrm{dv} / \mathrm{dt} * \mathrm{di} / \mathrm{dt}$ value to be calculated at relay ' $\mathrm{a}$ '. The $\mathrm{dv} / \mathrm{dt} * \mathrm{di} / \mathrm{dt}$ calculation relies on both $\mathrm{dv} / \mathrm{dt}$ changing simulateously, however the inductance of the line may interfere with this during a fault. The initial large di/dt resulting from F1 will induce a voltage on the line due to its inductive characteristic approximaltey equal to that of the steady state supply voltage. This induced voltage will cause relay ' $\mathrm{a}$ ' to see a negligble $\mathrm{dv} / \mathrm{dt}$ in the first moments of the fault. As a result, relay ' $a$ ' may not trip for F1 due to the interference with the $\mathrm{dv} / \mathrm{dt} * \mathrm{di} / \mathrm{dt}$ calculation. This will not be an issue for any fault downstrean of relay ' $b$ ' as a fraction of the total line induced voltage will occur upstrean of relay ' $b$ '. Therefore, relay ' $b$ '; will still see a $\mathrm{dv} / \mathrm{dt}$ immediatley after fault inception for all downstream faults.

\section{2) Application to a ring type d.c. network}

When applied in a radial network, a fault will either be downstream or upstream of the relay location. Meaning, for a fault, there will only be one path between the supply and the fault. This allows relay thresholds to be set as the direction of current flow within the network during a fault can be known prior to the fault. For a ring type network, the fault is both upstream and downstream of a relay simultaneously. The fault current flow within the network is also dependent on the fault location introducing issues for setting relay thresholds. This is demonstrated in Fig. 2. Assuming relay ' $h$ ' is downstream of relay ' $\mathrm{g}$ ' in terms of a reference current direction, F1 (which occurs directly at ' $h$ ') would be used to define relay ' $g$ 's operating threshold. F2 should trip relay ' $a$ ' and relay ' $b$ ' only. The main current flow from Converter 4 would pass through bus 5 for F1, assuming the network line lengths are symmetrical. However, for F2, the path of least resistance from converter 4 to $\mathrm{F} 2$ is through bus 3 . This redistribution of current flow will potentially make the thresholds that are set for relay ' $\mathrm{g}$ ' inapplicable for the scenario, resulting in unwanted tripping.

\section{3) Reliability against changes of sampling frequency}

As the protection scheme operates using rate of change of voltages and currents, the equipment sampling frequency will affect the protection sensitivity. Lowering of the sampling frequency will increase the timestep, therefore, the calculated 
$\mathrm{dv} / \mathrm{dt}$ and $\mathrm{di} / \mathrm{dt}$ values will be lower. This will significantly impact the performances of the combined dv/dt and di/dt based protection scheme. For example, if the sampling frequency is reduced and the relay threshold holds constant, it is likely that a fault will fail to be detected and located by the associated protection relay. If the sampling frequency is increased, the sensitivity of the relay is increased as measured $\mathrm{dv} / \mathrm{dt}$ and $\mathrm{di} / \mathrm{dt}$ magnitudes will become larger due to a smaller time step. However, this increase in sensitivity may cause undesired operation of other relays within the network, resulting in poor selectivity.

\section{MODEL OF D.C. TEST NETWORKS}

\section{A. Model of radial and ring d.c. networks}

All simulations are carried out using the parameters listed in TABLE I [1].

TABLE I. MODELLED D.C. DISTRIBUTION NETWORK PARAMETERS

\begin{tabular}{|c|c|}
\hline Parameters & Value \\
\hline Converter Supply Voltage & $750 \mathrm{~V}$ \\
\hline Current Limit & $1.2 \mathrm{p.u}$. \\
\hline Line Resistance & $0.164 \Omega / \mathrm{km}$ \\
\hline Line Inductance & $0.24 \mathrm{mH} / \mathrm{km}$ \\
\hline Sampling Frequency & $1 \mathrm{MHz}$ \\
\hline Fault Resistance & $0.01 \Omega$ \\
\hline Breaker Operating Time & $10 \mathrm{~ms}$ \\
\hline
\end{tabular}

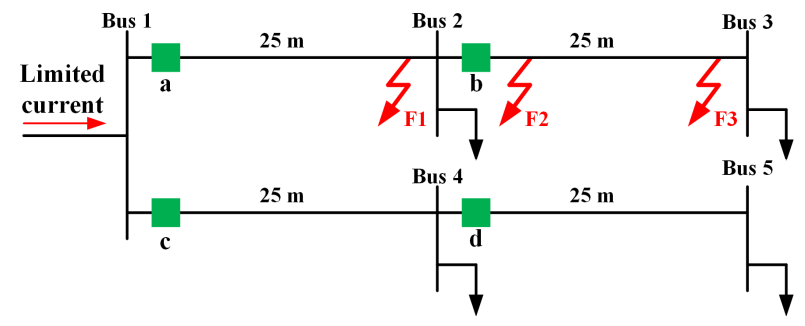

Fig. 1. Model of d.c. radial network

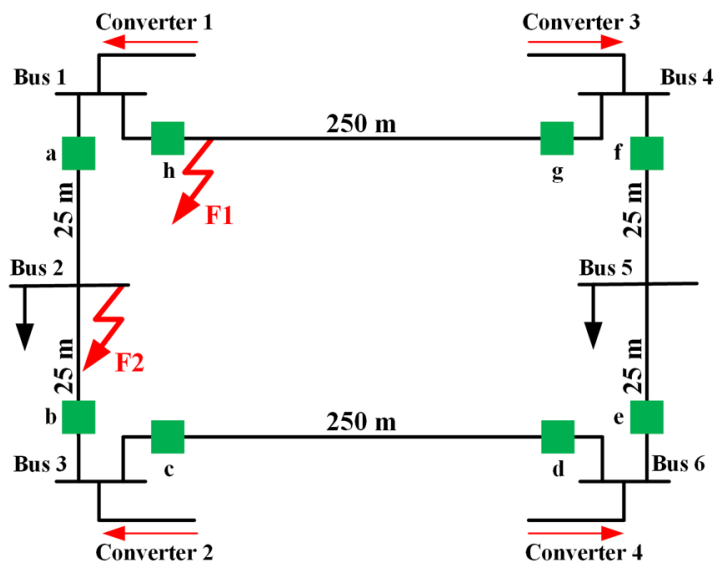

Fig. 2. Model of d.c. ring network

The d.c. networks detailed in Fig. 1 and Fig. 2 are built using PSCAD/EMTDC simulation programme. They are of shipboard scale with the dimensions based on the aircraft carrier Her Majesty's Ship (HMS) Queen Elizabeth [17]. For the radial network, Fig. 1, each cable section between two buses are $25 \mathrm{~m}$ in length. For the ring network, Fig. 2, all lines are 25 $\mathrm{m}$ except for the connections between buses 1 and 4 , and buses 3 and 6 , which are $250 \mathrm{~m}$ long.

\section{B. Simplified converter model with active fault current liming and blocking capabilities}

A simplified converter model with active fault current limiting and blocking behaviours is developed, shown in Fig. 3. The supply is modelled as a controlled current source with two reference voltages. The first reference is user defined and used to set the normal operating output voltage of the converter. The second reference is $0 \mathrm{~V}$ and is used during fault blocking operation. The actual output voltage $V_{1}$ is monitored and fed back to the controller.

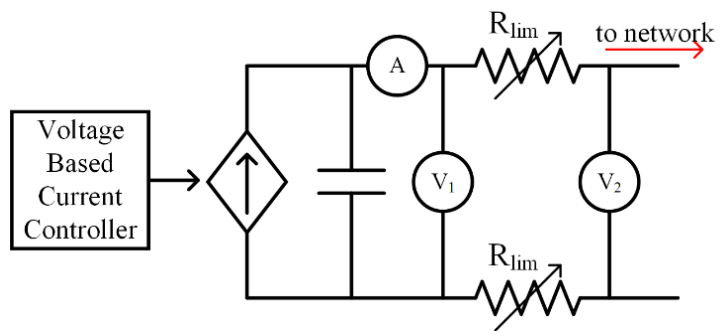

Fig. 3. Simplified converter model

During a fault condition, an additional resistance is introduced to the network to limit the fault current by increasing the value of variable resistances (shown as $\mathrm{R}_{\lim }$ Fig. 3). In normal operation, these resistances are set to $0 \Omega$. The additional resistance is used when the output current exceeds the user-defined current limit. The value of this resistance is based on system measurement ensuring the current would be limited to the same magnitude for all fault locations. To determine the required value of the resistances, $\mathrm{R}_{\mathrm{lim}}$, it is necessary to measure the voltage before, $\mathrm{V}_{1}$, and voltage after, $\mathrm{V}_{2}$, the variable resistors, as well as the output current, $\mathrm{I}_{\text {out }}$ A user-defined current limit, $\mathrm{I}_{\text {ref, }}$, is also set. The value of $\mathrm{R}_{\text {lim }}$ is calculated by subtracting the resistance of the faulted network from the value of resistance that would draw the desired limited current. Through manipulation of Ohm's law, (1) is derived to calculate $\mathrm{R}_{\text {lim. }}$.

$$
R_{\text {lim }}=\frac{1}{2}\left(\frac{V_{1}}{I_{\text {ref }}}-\frac{V_{2}}{I_{\text {out }}}\right)
$$

The converter behaviour is shown in Fig. 4, with a current limit of $350 \mathrm{~A}$.

When a d.c. pole-to-pole fault occurs at $t=0.1 \mathrm{~s}$, the fault current profile experiences a high transient as shown in in Fig. 4, followed by 350 A limited steady state fault current. There is then a time delay, based on the network's breaker operating times. If the fault is not cleared within this time, the converter's back-up operation is triggered. The network breakers successfully isolate the fault, at $\mathrm{t}=0.11 \mathrm{~s}$, the current rapidly declines, at which point the converter is reset. If the breakers fail to operate within the required time, the converter blocks all current (presented in Fig. 4 as dashed line). This is decided by 
monitoring $\mathrm{dv} / \mathrm{dt}$ where a positive $\mathrm{dv} / \mathrm{dt}$ would indicate voltage recovery and hence fault removal. At $\mathrm{t}=0.13 \mathrm{~s}$, the fault is isolated, and the converter is reset.

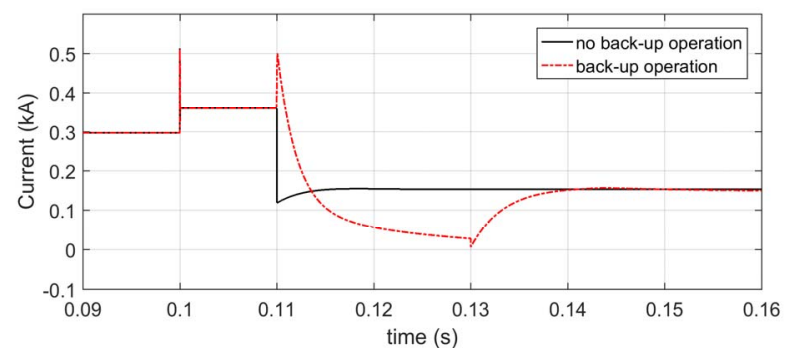

Fig. 4. Converter behaviour during pole-to-pole d.c. fault

\section{PERFORMANCE EVAlUATION OF THE COMBINED $\mathrm{dv} / \mathrm{dt}$ AND di/dt PROTECTION TECHNIQUE IN DIFFERENT FAULT SCENARIOS}

\section{A. Effectivenss of fault detection and location against different network configurations}

\section{1) Ring type d.c. network}

To investigate the combined $\mathrm{dv} / \mathrm{dt}$ and $\mathrm{di} / \mathrm{dt}$ protection technique performance in a ring compact network, the network in Fig. 2 is simulated. A pole-to-pole fault at location F1 (end of the line in respect to relay ' $g$ ') is applied, and the voltage and current profiles at relay ' $\mathrm{g}$ ' are monitored. The fault behavior as seen by relay ' $\mathrm{g}$ ' and shown in Fig. 5 is used to set the thresholds for the relay. The determined threshold values are listed in TABLE II.

TABLE II. RELAY G OPERATING THRESHOLDS

\begin{tabular}{|c|c|}
\hline Parameter & Operating Threshold \\
\hline $\mathrm{dv} / \mathrm{dt}$ & $6000 \mathrm{~V} / \mathrm{s}$ \\
\hline $\mathrm{dv} / \mathrm{dt} * \mathrm{di} / \mathrm{dt}$ & $60 \mathrm{E}+6 \mathrm{~V} / \mathrm{s} * \mathrm{~A} / \mathrm{s}$ \\
\hline
\end{tabular}

The recorded $\mathrm{dv} / \mathrm{dt}$ and $\mathrm{dv} / \mathrm{dt}^{*} \mathrm{di} / \mathrm{dt}$ show an initial transient followed by a period of zero rate of change before overshooting to higher transient magnitudes. This is a result of the network inductance and is similar behaviour to what has been seen in the radial network. As the network voltage collapses during a fault, the di/dt caused by the fault induces a voltage on the line approximately equal to the steady state network voltage. This causes the relay to see a reduced $\mathrm{dv} / \mathrm{dt}$ immediately following the fault as the measured voltage remains approximately the same. When a pole-to-pole fault is applied at location F2 (see Fig. 2), the protection thresholds for relay ' $g$ ' as illustrated in Fig. 6 are exceeded, causing the relay to trip undesirably.

The protection scheme expects that as the fault is moved further away from a relay, the measured $\mathrm{dv} / \mathrm{dt}$ and $\mathrm{dv} / \mathrm{dt} * \mathrm{di} / \mathrm{dt}$ will reduce. However, in this situation, the magnitudes have not reduced after a period of time when a fault happens. As the location of the fault has changed, the distribution of fault current flow in the network has also changed as there is an alternative path of least resistance. To relay ' $g$ ', this alternative fault current distribution results in the measuring of a larger $\mathrm{dv} / \mathrm{dt}$ and $\mathrm{dv} / \mathrm{dt} \mathrm{t}^{*} \mathrm{di} / \mathrm{dt}$ than the F1 fault, even though F1 is out with its desired reach, resulting in substandard protection selectivity.

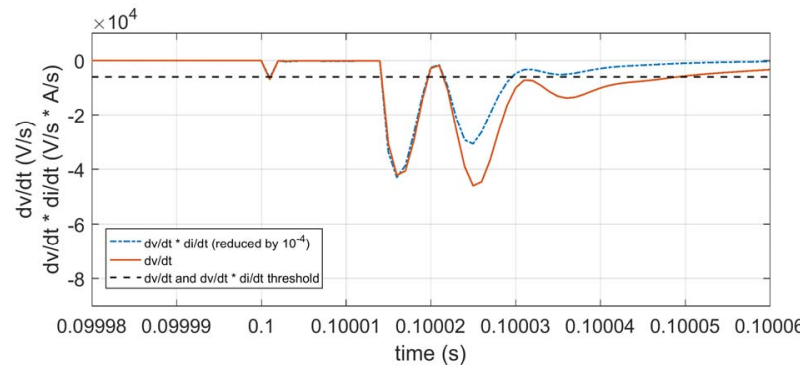

Fig. 5. Fault at location F1 as seen by relay ' $g$ '

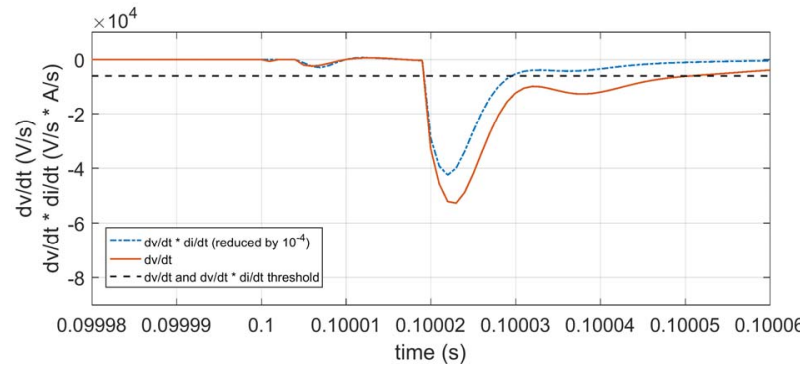

Fig. 6. Fault at location F2 as seen by relay ' $g$ '

\section{2) Radial type d.c. network}

\section{a) Effects of line induced voltage}

To test the effects of line induced voltage, the radial network shown in Fig. 1 is used and a pole-to-pole d.c. fault at location $\mathrm{F} 1$ is simulated. The voltage and current profiles at relay ' $a$ ' are monitored and used to investigate the relay response to this fault scenario.

The measured parameters of relay ' $a$ ' are presented in detail in Fig. 7. When the fault happens at $\mathrm{t}=0.1 \mathrm{~s}$, an immediate high di/dt is experienced. A voltage is also induced on the line approximately equal in magnitude to the steady state supply value. Paying attention to the area enclosed by the dashed circle, the $\mathrm{dv} / \mathrm{dt}$ is negligible which results in a dv/dt $* \mathrm{di} / \mathrm{dt}$ of almost zero. As both these quantities determine whether the relay should operate, this fault situation has significant impact on the protection scheme. Typical relay operation will show $\mathrm{dv} / \mathrm{dt}$ and $\mathrm{dv} / \mathrm{dt}^{*} \mathrm{di} / \mathrm{dt}$ as both negative, and simultaneously the magnitude of $\mathrm{dv} / \mathrm{dt} * \mathrm{di} / \mathrm{dt}$ would be larger than $\mathrm{dv} / \mathrm{dt}$. However, due the delay between a significant $\mathrm{di} / \mathrm{dt}$ measurement and a significant $\mathrm{dv} / \mathrm{dt}$ measurement, non-typical behaviour occurs.

One potential solution to this problem is the introduction of additional inductance between the converter and the relay. This is done by introducing a $2.5 \mathrm{~m}$ line segment. As the line induced voltage during the fault will be split upstream and downstream of the relay, there will be a noticeable $\mathrm{dv} / \mathrm{dt}$ measured by the relay, demonstrated in Fig. 8. From examining the area enclosed by the dashed circle in Fig. 8, it is apparent that the relay measures a more significant $\mathrm{dv} / \mathrm{dt}$ immediately after the fault. Also, the $\mathrm{dv} / \mathrm{dt} * \mathrm{di} / \mathrm{dt}$ value is more significant after that fault compared to the previous cases without 
additional inductance, which is typical to detect and locate downstream faults. This exact $\mathrm{dv} / \mathrm{dt}$ and $\mathrm{dv} / \mathrm{dt} * \mathrm{di} / \mathrm{dt}$ cobehaviour occurs once post-fault before the values settle to a steady state and is the expected behaviour of the relay for the downstream fault. Therefore, this event can be used to set the tripping thresholds of the relay.

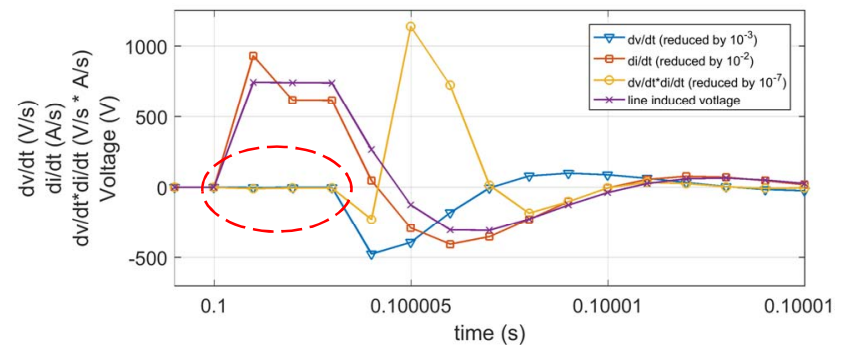

Fig. 7. Behaviour of $\mathrm{F} 1$ as seen by relay ' $\mathrm{a}$ ' - no additional inductance

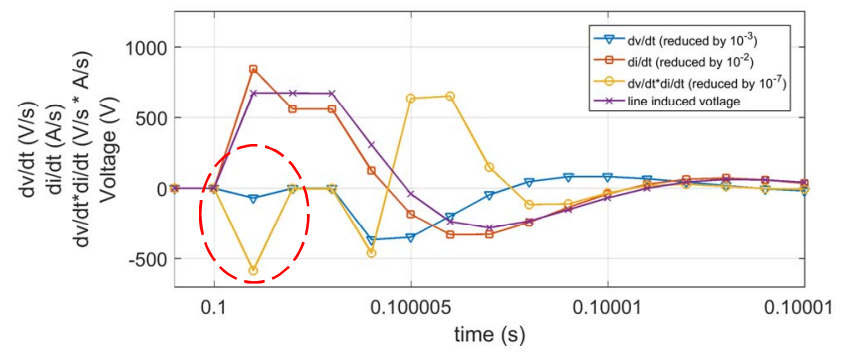

Fig. 8. Behaviour of F1 as seen by relay ' $a$ ' - with additional line reactance

\section{b) Effectiveness for faults either side of protection zone boudandary}

Referring to Fig. 1, the fault at location F2 will cause selectivity issues as relay 'a' sees negligible difference between F1 and F2 as demonstrated in Fig. 9. As both faults are practically identical to relay ' $a$ ', setting a threshold that will differentiate between the two locations will not be feasible.

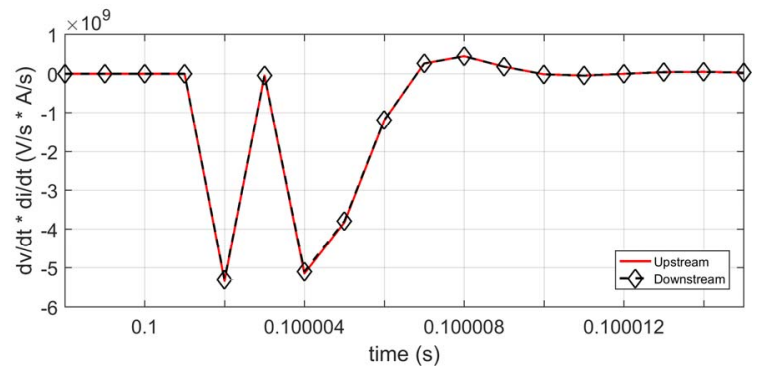

Fig. 9. dv/dt* di/dt measured by relay 'a' for pole-to-pole fault at locations F1 and F2 (radial network)

Two potential options to address this problem are using additional inductance to create additional margin to improve fault discrimination, or implementing a time delay. It has previosuly been demonstrated that additional inductance can be used to alter the $\mathrm{dv} / \mathrm{dt}$ behaviour of the network during a fault. Therefore, it could be used to change the $\mathrm{dv} / \mathrm{dt}$ and $\mathrm{dv} / \mathrm{dt} * \mathrm{di} / \mathrm{dt}$ magnitude of the fault at location F1 compared to location F2 allowing relay ' $a$ ' to discriminate between the two faults.

Another option to allow greater selectivty is the introduction of a time delay. For relay ' $a$ ', if a fault occurred on some last percentage of its line this would trigger a tripping time delay $(\Delta \mathrm{t})$, allowing relay ' $\mathrm{b}$ ' to operate first if the fault is in fact at F2. The time delay $(\Delta t)$ needs to be at least the operating time of the networks breakers (here this would be $10 \mathrm{~ms}$ ), to account for breaker operation and potential fault clearing, approximatley doubling the fault clearing time. By monitoring $\mathrm{dv} / \mathrm{dt}$, relay ' $\mathrm{a}$ ' can monitor voltage recovery and decide whether or not to operate. If the time delay times out and there is no voltage recovery it would either indicate protection failure or that the fault is upstream of relay ' $b$ ', and that relay ' $a$ ' should trip. As d.c. faults present harsh time constraints, the addition of a time delay in protection operation is not desirable. However, due to the limited fault currents, the implemention of a time delay is more feasible as the reduction of current will increase allowable operating times.

\section{B. Reliability against the changes of sampling frequency}

Sampling frequency is a characteristic of the relay, and not influenced by the network layout. Therefore, for simplicity, a pole-to-pole d.c. fault at location F3 is simulated on the radial network detailed in Fig. 1, and relay ' $b$ 's responses against changes of sampling frequency is examined. The recorded $\mathrm{dv} / \mathrm{dt}$ behaviour is detailed in Fig. 10.

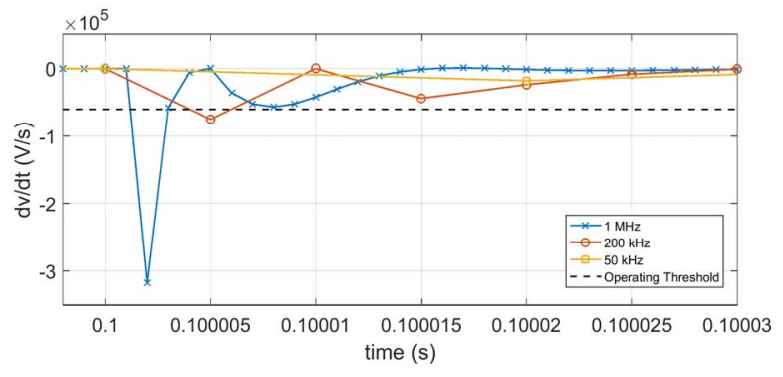

Fig. 10. Relay ' $b$ 's responses to F3 for a varied sampling frequency

As the sampling frequency is decreased, there is a decrease in $\mathrm{dv} / \mathrm{dt}$. Once decreased to $50 \mathrm{kHz}$, the $\mathrm{dv} / \mathrm{dt}$ value no longer exceeds the relay's operating threshold even though the fault is within its protected zone. This will likewise affect di/dt and $\mathrm{dv} / \mathrm{dt} * \mathrm{di} / \mathrm{dt}$. Therefore, if the relay threshold is not adjusted accordingly to a change in sampling frequency, sensitivity is reduced and the protection scheme may fail.

\section{CONCLUSIONS}

The paper has investigated in detail the effectiveness of utilising the combined $\mathrm{dv} / \mathrm{dt}$ and di/dt d.c. protection technique for protecting compact d.c. distribution systems with radial and ring configurations. It has been found that the technique's selectivity and sensitivity can be considerably impacted by the variations of fault location, sampling frequency, and network architecture. The main bus protection devices in a radial network can be susceptible to undesired $\mathrm{dv} / \mathrm{dt}$ behaviour due to line induced voltage during faults causing interference with the 
$\mathrm{dv} / \mathrm{dt} * \mathrm{di} / \mathrm{dt}$ calculations. The alteration of sampling frequency has a direct effect on the relay's $\mathrm{dv} / \mathrm{dt}$ and $\mathrm{di} / \mathrm{dt}$ calculations. If sampling frequency is not considered when selecting thresholds, it could result in protection failure due to a change in sensitivity. In a radial network, when considering a relay downstream of the main bus protection devices, the protection scheme has trouble discriminating between upstream and downstream and may trip for both faults. Application in a ring network resulted in failure of the protection system. The associated relay may measure smaller $\mathrm{dv} / \mathrm{dt}$ and $\mathrm{di} / \mathrm{dt}$ values for a fault within its protected zone and larger values for a fault that is out with its protected zone. This results in protection failure unless the fault occurs at the location on which the relay thresholds are set.

Based on this investigation, it has been concluded that the effective use of the combined $\mathrm{dv} / \mathrm{dt}$ and $\mathrm{di} / \mathrm{dt}$ technique is currently limited to a radial network.

\section{REFERENCES}

[1] D. Wang, A. Emhemed and G. Burt, "A novel protection scheme for an LVDC distribution network with reduced fault levels," 2017 IEEE Second International Conference on DC Microgrids (ICDCM), Nuremburg, 2017.

[2] M. Belkhayat, "Ship Electrification: DC Versus AC and the Rise of Digital Power [Technology Leader]," IEEE Electrification Magazine, vol. 5, no. 3, pp. 88, 84-86, Sept. 2017.

[3] D. Bosich, A. Vicenzutti, R. Pelaschiar, R. Menis and G. Sulligoi, "Toward the future: The MVDC large ship research program," 2015 AEIT International Annual Conference (AEIT), Naples, 2015.

[4] Z. Wang, Z. Chen and X. Wang, "Research of the DC microgrid topology," 2016 Chinese Control and Decision Conference (CCDC), Yinchuan, 2016.

[5] A. A. S. Emhemed, K. Fong, S. Fletcher and G. M. Burt, "Validation of Fast and Selective Protection Scheme for an LVDC Distribution Network," in IEEE Transactions on Power Delivery, vol. 32, no. 3, pp. 1432-1440, June 2017.

[6] M. Winkelnkemper, L. Schwager, P. Blaszczyk, M. Steurer and D. Soto, "Short circuit output protection of MMC in voltage source control mode," 2016 IEEE Energy Conversion Congress and Exposition (ECCE), Milwaukee, WI, 2016.

[7] K. Satpathi, A. Ukil and J. Pou, "Short-Circuit Fault Management in DC Electric Ship Propulsion System: Protection Requirements, Review of Existing Technologies and Future Research Trends," in IEEE Transactions on Transportation Electrification, vol. 4, no. 1, pp. 272-291, March 2018.

[8] O. Alnes, S. Eriksen and B. J. Vartdal, "Battery-Powered Ships: A Class Society Perspective," in IEEE Electrification Magazine, vol. 5, no. 3, pp. 10-21, Sept. 2017.

[9] A. Vicenzutti, D. Bosich, G. Giadrossi and G. Sulligoi, "The Role of Voltage Controls in Modern All-Electric Ships: Toward the all electric ship.," in IEEE Electrification Magazine, vol. 3, no. 2, pp. 49-65, June 2015.

[10] G. Sulligoi, A. Vicenzutti and R. Menis, "All-Electric Ship Design: From Electrical Propulsion to Integrated Electrical and Electronic Power Systems," in IEEE Transactions on Transportation Electrification, vol. 2, no. 4, pp. 507-521, Dec. 2016.

[11] IEEE Recommended Practice for $1 \mathrm{kV}$ to $35 \mathrm{kV}$ Medium-Voltage DC Power Systems on Ships," in IEEE Std 1709-2010, pp.1-54, Nov. 2010.

[12] R. Ma et al., "Investigation on Arc Behavior During Arc Motion in Air DC Circuit Breaker," in IEEE Transactions on Plasma Science, vol. 41, no. 9, pp. 2551-2560, Sept. 2013.

[13] C. Gu, P. Wheeler, A. Castellazzi, A. J. Watson and F. Effah, "Semiconductor Devices in Solid-State/Hybrid Circuit Breakers: Current Status and Future Trends," Energies, vol. 10, no. 4, Apr. 2017.

[14] Z. J. Shen, Z. Miao and A. M. Roshandeh, "Solid state circuit breakers for DC micrgrids: Current status and future trends," 2015 IEEE First International Conference on DC Microgrids (ICDCM), Atlanta, GA, 2015.

[15] Y. Zhong, N. Roscoe, D. Holliday, T. C. Lim and S. J. Finney, "HighEfficiency mosfet-Based MMC Design for LVDC Distribution Systems," in IEEE Transactions on Industry Applications, vol. 54, no. 1, pp. 321334, Sept. 2017.

[16] S. D. A. Fletcher, P. J. Norman, K. Fong, S. J. Galloway and G. M. Burt, "High-Speed Differential Protection for Smart DC Distribution Systems," in IEEE Transactions on Smart Grid, vol. 5, no. 5, pp. 2610-2617, Sept. 2014.

[17] "Queen Elizabeth Class | Royal Navy", Web.archive.org, 2013. [Online]. Available:https://web.archive.org/web/20130810221625/http://www.roy alnavy.mod.uk/The-Fleet/Ships/Future-Ships/Queen-Elizabeth-Class. [Accessed: 24 May 2018] 